\title{
LIVROS DIDÁTICOS DO ENSINO MÉDIO E O CONHECIMENTO ESCOLAR SOBRE MUDANÇAS CLIMÁTICAS
}

\author{
Luciane Cortiano Liotti ${ }^{1}$ \\ Marília Andrade Torales Campos²
}

Resumo: Este artigo analisa em que medida o conhecimento escolar sobre Mudanças Climáticas (MC), abordado nos Livros Didáticos (LD) do Ensino Médio, pode contribuir para que os estudantes construam concepções científico-sociais, econômicas e políticas sobre este fenômeno que afeta a sociedade global. Apresenta-se uma análise dos dados, considerando três critérios: os conteúdos textuais, as iconografias e as propostas de atividades. Por meio dos dados produzidos, verificou-se a falta de uma abordagem interdisciplinar e contextualizada sobre essa temática nos materiais de ensino, fato que dificulta a compreensão do fenômeno das mudanças climáticas em sua totalidade pelos estudantes.

Palavras-chave: Educação Básica; Currículo; Conhecimento Escolar; Educação Ambiental.

Abstract: This article analyzes the extent to which school knowledge on Climate Change (CC), addressed in High School Textbooks (ST), can contribute to students in the building of scientific-social, economic and political conceptions about this phenomenon that affects global society. An analysis of the data is presented considering three criteria: textual content, iconographies and activity proposals. By the means of the data produced, a lack of an interdisciplinary and contextualized approach was found on this topic in the teaching materials, a fact that makes it difficult for students to understand the phenomenon of climate change in its entirety.

Keywords: Basic Education; Curriculum; School Knowledge; Environmental Education.

\footnotetext{
1 Universidade Federal do Paraná. Secretaria de Estado da Educação. E-mail: luliotti@gmail.com, Link para o Lattes: http://lattes.cnpq.br/4788849966931886

2. Universidade Federal do Paraná. Professora Associada. E-mail: mariliat.ufpr@gmail.com. Link para o Lattes: http://lattes.cnpq.br/7576748068658968
} 


\section{Introdução}

Diante das crescentes evidências de vulnerabilidade do Planeta e das diferentes situações de degradação ambiental, uma série de desafios insurgem e não permitem tergiversar sobre suas consequências para a vida e para as sociedades contemporâneas. No bojo da problemática ambiental do século $\mathrm{XXI}$, as situações que envolvem as mudanças climáticas constituem-se no problema central e mais relevante. Suas causas e consequências, ainda que pouco conhecidas da população, exigem o recrudescimento de esforços para ampliar a consciência sobre sua existência e significado. Mais especificamente, a sociedade, como não está incólume a este processo, precisa reivindicar a constituição de políticas públicas e educativas que integrem objetivos convergentes em prol do desenvolvimento de uma gestão das sociedades para que compreendam a vulnerabilidade dos sistemas naturais (LIMA; LAYRARGUES, 2014).

Considerando a dimensão humana da crise como fundamental para a compreensão das mudanças climáticas, sabe-se que há necessidade de mudarmos os hábitos de consumo, produção e distribuição de riqueza, pois os problemas socioambientiais requerem também uma resposta de caráter ecosocial.

Um dos desafios da Educação Ambiental para o século XXI é a inserção da temática das mudanças climáticas no debate cotidiano das comunidades e sociedades. Para ampliar as possibilidades de compreensão dos complexos conceitos construídos pelas Ciências, é preciso incentivar um processo de comunicação científica capaz de ampliar a consciência social sobre o problema e promover a participação e co-responsabilização de todos em relação aos processos de adaptação e mitigação dos impactos das mudanças climáticas, incluindo o desenvolvimento de estratégias de resistência. Assim, a Educação Ambiental torna-se uma estratégia de ação importante para promover a mudança de determinados modos de agir e pensar como alternativas para a construção de sociedades mais sustentáveis.

Observando o conjunto de alterações climáticas no sistema climático, o Painel Intergovernamental sobre Mudanças Climáticas (IPCC) ${ }^{3}$ vem alertando, desde a sua criação em 1988, sobre as evidências das influências antrópicas no clima e a forma como elas se manifestam: a intensificação do efeito estufa, a constatação do aumento da concentração do dióxido de carbono $\left(\mathrm{CO}_{2}\right)$ na atmosfera, o derretimento das calotas polares, o aumento do nível do mar, a disponibilidade de água doce, entre outros fatores, os quais representam apenas alguns exemplos que têm reforçado estudos científicos para avaliar até

3 IPCC: Da sua denominação em inglês "Intergovernmental Panel on Climate Change". Tem como objetivo principal sintetizar e divulgar o conhecimento mais avançado sobre as mudanças climáticas que hoje afetam o mundo, especificamente, o aquecimento global, apontando suas causas, efeitos e riscos para a humanidade e o meio ambiente, e sugerindo maneiras de combater os problemas. É organizado em três Grupos de Trabalho (GT), designados no sob os temas: GT1 - "bases da ciência física"; GT2 "impactos, adaptação e vulnerabilidade"; e GT3 - "mitigação da mudança climática" (LEITE, 2015, p. 644). 
que ponto a atividade humana pode interferir adversamente em relação aos ecossistemas que dão suporte à vida humana e a todos os seres vivos do Planeta (STEFFEN et al. 2011).

A crise ambiental instaurada, portanto, revela-se como problema socioambiental de alta complexidade e exige uma postura crítica e protagonista dos sujeitos para a compreensão mais profunda de suas origens e das evidências de que essa situação é reflexo do modelo de desenvolvimento adotado pelas sociedades contemporâneas.

Neste contexto, a crise ambiental mostra seu caráter global e conflitivo, pois se manifesta como um problema econômico, político e tecnológico, o qual deveria estar em evidência em todas as agendas nacionais e internacionais Também se trata de um problema social, ecológico, ético-cultural, pois afeta de forma desigual, tanto em nível territorial (zonas tropicais, ilhas, zonas costeiras), como em nível de coletivos sociais (comunidades agrícolas, indígenas e pesqueiras), pessoas socialmente excluídas que vivem nas periferias dos grandes centros; e, ademais, apresenta-se como um problema extremamente desigual porque os principais setores responsáveis pelo consumo massivo de recursos e de emissão dos Gases de Efeito Estufa (GEE) sofrerão as consequências das mudanças climáticas em menor proporção do que as sociedades/comunidades que vivem em situação de vulnerabilidade socioambiental, que são as que menos tem contribuído para essa situação (SERANTES-PAZOS; MEIRA-CARTEA, 2016).

Esse cenário exige a necessidade da organização de caminhos alternativos para o enfrentamento desse fenômeno. Nesse sentido, a Educação é considerada como um dos processos do desenvolvimento humano responsável pela organização do conhecimento, pela mudança de mentalidade, bem como pela formação de novas identidades sociais. Para Carvalho, Tomazello e Oliveira (2009, p. 14):

A educação é um caminho reconhecido por todos como de grande significado na compreensão e na busca de soluções para os complexos e diversificados problemas relacionados com as alterações ambientais provocadas pelas atividades humanas.

Há portanto, um consenso sociocultural em reconhecer o processo educativo ${ }^{4}$ como uma possibilidade de provocar alterações no atual quadro de

\footnotetext{
${ }^{4}$ Processo Educativo: Por saber que o processo educativo envolve os métodos e materiais educacionais relacionados com a escolarização em todos os seus aspectos teóricos e práticos, como os que abrangem o processo de aprendizagem, os métodos de ensino, o sistema de avaliação da aprendizagem e o sistema educacional, esclarecemos o uso desse conceito nessa Tese para pensar a organização curricular do Ensino Médio e o reconhecimento do papel do livro didático no cenário educativo (LIOTTI, 2019, p. 32).
} 
degradação socioambiental no contexto escolar, tendo o livro didático como material de ensino que organiza os conteúdos escolares, veiculando conhecimento sistematizado e legitimado na educação básica, de maneira a atender a cada componente curricular, em cada nível e modalidade de ensino, oferecendo suporte metodológico e estruturador à prática docente na relação de ensino-aprendizagem (BITENCOURT, 2004; LIOTTI, 2019).

Nesse contexto há o reconhecimento da Educação como uma ferramenta necessária para contribuir com o enfrentamento das mudanças climáticas e, sem dúvida, a Educação Ambiental (EA) é um dos meios para avançar na formação da cidadania. A Educação Ambiental oportuniza o debate e o questionamento, trazendo reflexões sobre as consequências das alterações ambientais climáticas. De acordo com Lima e Layrargues, (2014, p. 81-82) o processo educativo pode:

\begin{abstract}
[...] imprimir um olhar complexo ao problema, nem sempre presente nas análises mais apressadas; pode agregar informação de qualidade à comunicação pública, dirimir falsas controvérsias e com isso facilitar a inclusão do educando no debate em curso, em ações cotidianas e na participação em movimentos orientados à questão climática. Enfim, os processos educativos podem ampliar a compreensão do fenômeno climático, de sua gênese histórica, de suas causas estruturantes, de suas múltiplas dimensões, em especial as condicionantes políticas e culturais menos aparentes e das alternativas de sua superação, disponíveis para os indivíduos, grupos, movimentos sociais, empresas e governos.
\end{abstract}

Esta afirmação corrobora e fortalece o papel da Educação Ambiental como mediadora na constituição de práticas ambientais educativas centradas na criticidade e na emancipação dos sujeitos frente aos problemas socioambientais, contribuindo na superação da crise climática, com vistas ao desenvolvimento de uma sociedade contemporânea mais crítica, justa e igualitária, capaz de proporcionar a superação da visão positivista, antropocêntrica e tecnocrática, tendo como objetivo, dentre outros, a redução do consumismo desenfreado e a pobreza extrema (MININNI-MEDINA, 2002).

Tendo em vista o papel da escola e os saberes transmitidos por ela e dada a importância pedagógica do livro didático como um dos representantes da expressão e materialização da linguagem da Ciência na escola e reconhecido na cultura escolar como um dos principais recursos de apoio ao trabalho docente, decidiu-se pesquisar a temática das Mudanças Climáticas nos Livros Didáticos.

Ciente de que essa é uma questão complexa não só para a educação, mas também para a comunidade científica, nesta pesquisa analisou-se em que medida o conhecimento escolar sobre Mudanças Climáticas, abordado nos 
Livros Didáticos de Biologia, Física, Química e Geografia - PNLD/ 2015, podem contribuir para que os estudantes construam suas concepções sobre este fenômeno.

É justamente nessa relação entre o livro didático e a temática das mudanças climáticas que se inscreve a problemática dessa investigação, pois, pesquisar que tipo de conhecimento escolar sobre mudanças climáticas é abordado nos livros didáticos do Ensino Médio, nos auxilia a compreender e a enxergar se o conhecimento contido nesse material didático pode contribuir com o aprofundamento teórico-científico necessário, a fim de auxiliar o trabalho do professor na formação de sujeitos capazes de (re) pensar sua concepção de sociedade, de mundo, de homem e de natureza, preparando-os para o enfrentamento da crise socioambiental estabelecida (FRACALANZA; MEGIDNETO, 2006; TEIXEIRA, 2011; LIOTTI, 2019).

\section{O livro didático e as mudanças climáticas}

O sistema educativo, especificamente a escola, desempenha um papel fundamental na construção social da realidade através das informações e conhecimentos que propicia aos estudantes. Nesse processo, os livros didáticos tornam-se, portanto, material constituinte da organização dos conteúdos curriculares e, por conseguinte, um objeto revelador entre a interconexão dos conhecimentos científicos e o conhecimento escolar (LOPES, 1999; FREITAS, RODRIGUES, 2007; CHOI et al., 2010, p. 890; TEIXEIRA, 2011).

Autores como Apple (1997) e Giroux (2001) nos lembram de que o livro didático é um dos instrumentos de legitimação do conhecimento científico na escola e apresentam uma visão da realidade que corresponde à didatização do conhecimento científico propostos nos documentos curriculares oficiais orientadores. Segundo Lopes (2007), a didatização é um processo de reconstrução de saberes, a fim de tornarem-se acessíveis aos estudantes na instituição escolar, permitindo identificar as finalidades sociais do conhecimento e da educação, compreendendo as relações de poder que se estabelecem nesse contexto (LIOTTI, 2019).

Além do caráter pedagógico do livro didático, é preciso ter consciência do seu aspecto comercial, visto que esse material é considerado um produto decorrente do mercado editorial que foi criado para atender ao Programa Nacional do Livro Didático $(P N L D)^{5}$, no qual as transações comerciais de

\footnotetext{
5 PNLD: Programa Nacional do Livro Didático, implantado pelo Decreto n. 7.084, de 27 de janeiro de 2010 e pela Resolução MEC/FNDE n.ำ 42, de 28 de agosto de 2012, que inseriu o PNLEM ao PNLD, executado pelo FNDE (Fundo Nacional de Desenvolvimento da Educação) e pela Secretaria de Educação $\begin{array}{llll}\text { Básica (SEB/MEC). } & \text { (BRASIL/FNDE, 2012). } & \text { Disponível } & \text { em: }\end{array}$ $<$ https://www.fnde.gov.br/index.php/resolucoes/2012>. Acesso em: 03 ago. 2020.
} 
produção e consumo constituem-se como condição material de sua existência. Esse controle se torna uma das estratégias de manutenção do poder sobre quais conhecimentos serão selecionados, dentre os socialmente disponíveis, para compor o currículo e os livros didáticos, traduzindo-se numa suposta obsolescência dos conteúdos que estão presentes nesse material de ensino.

Destaca-se segundo Apple (1993), que os livros didáticos não são neutros porque apresentam uma única leitura (e simplificada) da realidade, ou simplesmente não abordam temas socialmente relevantes e conflitivos em detrimentos de outros conhecimentos. Isto decorre, segundo o autor, porque os livros didáticos representam interesses editoriais e ideologias políticas concretas que determinam que «eles» sejam organizados assim. Apple (1993, p. 110) salienta também que "o que consideramos conhecimento legítimo é, pelo contrário, o resultado de complexas relações de poder e de lutas de classe, raças, sexos e grupos religiosos identificáveis". Reforça-se claramente que esse conhecimento, ao ser publicado, legitima mais uma vez o binômio educação-poder. No mesmo sentido, Gatti-Júnior (1997, p. 36) evidencia que os livros didáticos são produzidos em série, considerados como "fiéis depositários das verdades científicas universais", as quais foram se consolidando ao longo do tempo.

Apple (1995), Batista (1999), Martins (2012) afirmam que o livro didático expressa e materializa o conhecimento que a sociedade reconhece como legítimo e verdadeiro, contribuindo para determinar os padrões da veracidade sobre determinado tema. Nesse sentido, o livro didático constitui-se um ponto de referência para saber o que a sociedade considera como conhecimento, cultura, crenças e moralidade, e identificar como manifesta uma visão neoliberal e de desenvolvimento que responde a economia global de mercado, ignorando outros modelos socioeconômicos viáveis e contra hegemônicos.

Também é preciso considerar que os livros didáticos têm um viés disciplinar acentuado, enquanto a temática das mudanças climáticas exige uma conexão do sistema natural com os sistemas econômico, social, político e técnico, por isso torna-se difícil mostrar esse problema aos estudantes, se não a partir de uma abordagem interdisciplinar.

Nesse sentido, o livro didático é um material de ensino complexo, que afeta a vida cotidiana das escolas, de diferentes formas e em diferentes situações, produzindo variadas experiências escolares, e segundo, Bittencourt (2015, p. 73) para analisá-lo não basta observar "as ideologias e as defasagens de conteúdos em relação à produção acadêmica ou descobrir se o material é fiel ou não às propostas curriculares". Para entender este material com profundidade é preciso ampliar a interpretação e levar em consideração outros 
aspectos e contradições, como um sistema integrado de signos com diferentes significados e linguagens - um híbrido semiótico ${ }^{6}$.

Reconhecendo-se que esse material de ensino é portador de textos de diferentes constituições linguísticas, heterogêneo quanto à sua constituição simbólica a partir da presença de uma diversidade de linguagens, seja ela verbal (texto escrito, atividades), matemática (equações, gráficos, notações), iconográficas (desenhos, fotografias, mapas, diagramas), que em conjunto formam um sistema de significação dos textos, abre-se espaço para análise e questionamentos do papel de outros modos, além do verbal, na construção do conhecimento em Ciência na educação. Portanto, se reafirma que o foco desta pesquisa foi analisar em que medida o conhecimento escolar sobre mudanças climáticas, abordado nos livros didáticos do ensino médio, podem contribuir para que os estudantes construam concepções científico-sociais, econômicas e políticas sobre este fenômeno.

\section{Percurso para a realização da pesquisa}

Seguiu-se a metodologia de análise de conteúdo proposta por Bardin (2008), que permite examinar o significado das mensagens a partir de uma descrição objetiva, sistemática e quantitativa do conteúdo, tanto textual quanto iconográfico, para problematizar a dimensão social da linguagem, questões de autoridade e poder da linguagem da Ciência. O texto dos livros didáticos "não são a transposição [simples] transparente de opiniões, atitudes $e$ representações que existem definitivamente antes da transição para a forma textual" (BARDIN, 2008, p. 216); são modos de representações dos aspectos do mundo que explicitam as identidades socioculturais, as posições dos sujeitos, as relações sociais, os sistemas de conhecimento e as crenças.

Analisou-se os livros didáticos, manuais do professor $^{7}$, dos livros de Química, Física, Biologia e Geografia (sendo 3 livros, um para cada série do Ensino Médio) presentes no Guia de Livros Didáticos de Educação do PNLD / 2015, do triênio 2015-2017, para as escolas do município de Curitiba/PR, totalizando 12 (doze) livros analisados.

Para analisar o que e como os livros didáticos do ensino médio abordam a temática das mudanças climáticas (suas tensões, erros e ausências), como mediadores da aprendizagem, focou-se a análise das informações,

\footnotetext{
${ }^{6}$ Semiologia é a ciência geral dos signos. A palavra vem da união das palavras gregas semeion, que significa sinal, e logos, estudo. A Semiologia é uma área do conhecimento que se dedica a compreender os sistemas de significação desenvolvidos pela sociedade. Tem por objeto os conjuntos de signos, sejam eles linguísticos, visuais, ou ainda ritos e costumes Disponível em: $<$ https://www.significados.com.br/semiologia/>. Acesso em: 03 ago. 2020.

${ }^{7}$ Manuais do professor: Analisou-se estes livros pois estes devem conter instruções e orientações teóricometodológicas ao professor e de articulação dos conteúdos do livro entre si e com outras áreas do conhecimento, acompanhadas do livro do estudante de forma integral, com ou sem comentários adicionais (LIOTTI, 2019, p. 160).
} 
considerando três níveis: os conteúdos textuais, as iconografias e as propostas de atividades apresentados resumidamente na Tabela 1:

1. Análise do conteúdo "sistemático, objetivo e quantitativo" (BARDIN, 2008). Codificou-se as informações manualmente com um sistema emergente de categorias, de forma aberta e com base em critérios próprios, especificados em categorias e subcategorias que permitiram posteriormente identificar as unidades de registro e unidades de contexto dos excertos selecionados para análise (LIOTTI, 2019).

2. Análise iconográfica para identificar mensagens, conceitos, ideias, valores que, além do aparente caráter ilustrativo, acrescentam informações adicionais e reforçam uma leitura combinada entre texto e imagem (MARTINS, 2012, apud LIOTTI, 2019, p. 171; PRALON, 2012).

3. Atividades propostas para os alunos como forma de promover a aprendizagem em termos de conteúdo, procedimentos e valores.

Tabela 1: Categorias e subcategorias de análise.

\begin{tabular}{llllll} 
CATEGORIAS & \multicolumn{4}{c}{ SUBCATEGORIAS } \\
Conteúdo textual & Definição & Causas & Consequências & Medidas \\
\hline Conteúdo iconográfico & Fotografias & $\begin{array}{l}\text { Esquemas/ } \\
\text { llustração }\end{array}$ & Gráficos & Mapas \\
\hline Atividades propostas & $\begin{array}{l}\text { Reprodução } \\
\text { de conteúdo }\end{array}$ & $\begin{array}{l}\text { Interpretação de } \\
\text { Dados/lnvestigativa }\end{array}$ & $\begin{array}{l}\text { Pesquisa/ } \\
\text { debate }\end{array}$ & discussão e e & \\
\hline
\end{tabular}

Fonte: Liotti (2019).

Para organizar e identificar o conteúdo dos livros didáticos a serem analisados, cada livro recebeu um código de identificação que permite por meio dele reconhecer: a disciplina, o número do volume, os dados editoriais, a unidade, o capítulo, o subtítulo e a seção da qual pertence o texto extraído. Ao lado de cada código há uma letra minúscula indicando a qual categoria aquele excerto de texto pertence, ou seja: (d)-definição; (c)-causa; (cs)-consequência; (mt)-medidas de mitigação e (sa)-sugestão de atividade, como apresentado a seguir na Tabela 2: 
Tabela 2: Modelo para identificar os livros didáticos e os conteúdos (exemplo).

\begin{tabular}{lclllllll}
\hline Disciplina & Vol & Editora & Ano & Unidade & Capítulo & Sub-título & Seção & Código \\
\hline Biologia & 3o & Ática & 2014 & $\begin{array}{l}4 . \\
\text { Ecologia }\end{array}$ & $\begin{array}{l}\text { 15. Ciclos } \\
\text { Biogeoquí- } \\
\text { micos }\end{array}$ & $\begin{array}{l}\text { 1: Ciclo do } \\
\text { Carbono }\end{array}$ & $\begin{array}{l}\text { C: } \\
\text { Aquecimento } \\
\text { global: } \\
\text { possíveis } \\
\text { consequências } \\
\text { (p.202-203) }\end{array}$ & B3.15.1.C(cs) \\
\hline Física & 10 & FTD & 2013 & Dinâmica & 10. Energias & $\begin{array}{l}\text { 1: Trabalho } \\
\text { de uma força }\end{array}$ & $\begin{array}{l}\text { Obtenção de } \\
\text { Energia } \\
\text { (p.192-193) }\end{array}$ & F1.10.1(c) \\
\hline
\end{tabular}

Fonte: Liotti (2019).

A partir da construção da tabela com os textos selecionados e codificados (Tabela 2), os conteúdos textuais foram reorganizados em tabelas estruturadas, seguindo as categorias de análise (Tabela 1), as quais serão apresentadas a seguir:

A Tabela 3 (Análise de Conteúdo Textual) traz o recorte dos textos em elementos menores, as unidades de registro (UR), que correspondam a unidades de significação relacionadas ao tema de estudo, e as unidades de contexto (UC), que correspondem às mensagens específicas contidas em cada excerto, podendo ser uma frase, palavra ou parágrafo relacionado ao tema estudado - mudanças climáticas - e referentes às subcategorias: definição(d), causas(c), consequências (cs) e medidas(mt) (mitigação/adaptação) encontradas nos livros didáticos analisados:

Tabela 3: Análises de Conteúdo Textual (exemplos de causas (c) e definição (d) das MC).

\begin{tabular}{|c|c|}
\hline CODIGO & UNIDADE DE REGISTRO/ CONTEXTO \\
\hline B3.15.1A(c) & $\begin{array}{l}\text { A luz do Sol passa pelo vidro e é absorvida pelas plantas e por outros objetos, que se } \\
\text { aquecem e emitem raios infravermelhos. Essa emissão é também chamada radiação, } \\
\text { onda infravermelha ou, ainda, radiação térmica. De maneira semelhante ao que ocorre } \\
\text { na estufa de plantas, as radiações do Sol passam pela atmosfera e esquentam a } \\
\text { superfície do planeta, que emite raios infravermelhos. Desse modo, a atmosfera mantém } \\
\text { a temperatura do planeta nos níveis que conhecemos hoje }(\mathrm{B} 3,2014, \mathrm{p} \text {. } 200) \text {. O efeito } \\
\text { estufa mantém a temperatura média da Terra em torno de } 15{ }^{\circ} \mathrm{C} \text { e, sem ele, o planeta } \\
\text { estaria permanentemente coberto por uma camada de gelo e sua temperatura média estaria } \\
\text { em torno de }-18^{\circ} \mathrm{C} \text {. Diversos gases na atmosfera colaboram para o efeito estufa, entre } \\
\text { eles: o vapor de água, o gás carbônico, o gás metano, o dióxido de nitrogênio e os } \\
\text { clorofluorcarbonos (CFCs). O gás carbônico é o principal gás para o efeito estufa, } \\
\text { sendo responsável por cerca de } 63 \% \text { do efeito, que em grande escala causa a sua } \\
\text { intensificação (B3, } 2014, \text { p. } 200) \text {. }\end{array}$ \\
\hline Q1. UN.1(d) & $\begin{array}{l}\text { Mudanças Climáticas são alterações que vêm sendo observadas no clima do planeta, como } \\
\text { mudanças no regime de chuvas, enchentes, estiagens, aumento ou diminuição da } \\
\text { temperatura média em continentes e/ou oceanos, aumento na frequência de tornados e } \\
\text { furacões, derretimento de geleiras, calor excessivo, frio extremo, etc. (Q1, 2014, p.16). }\end{array}$ \\
\hline
\end{tabular}

Fonte: Liotti (2019). 
A Tabela 4 (Análise de Conteúdo Iconográfico) apresenta a seleção das iconografias presentes nos textos selecionados - unidades de registro (UR) referentes às subcategorias: fotografias; esquemas/ilustrações; gráficos e mapas, buscando entre estes elementos e os textos informações adicionais e essenciais que podem servir como uma fonte auxiliar e necessária na compreensão do fenômeno das mudanças climáticas.

Tabela 4: Análises de Conteúdo Iconográfico (exemplo).

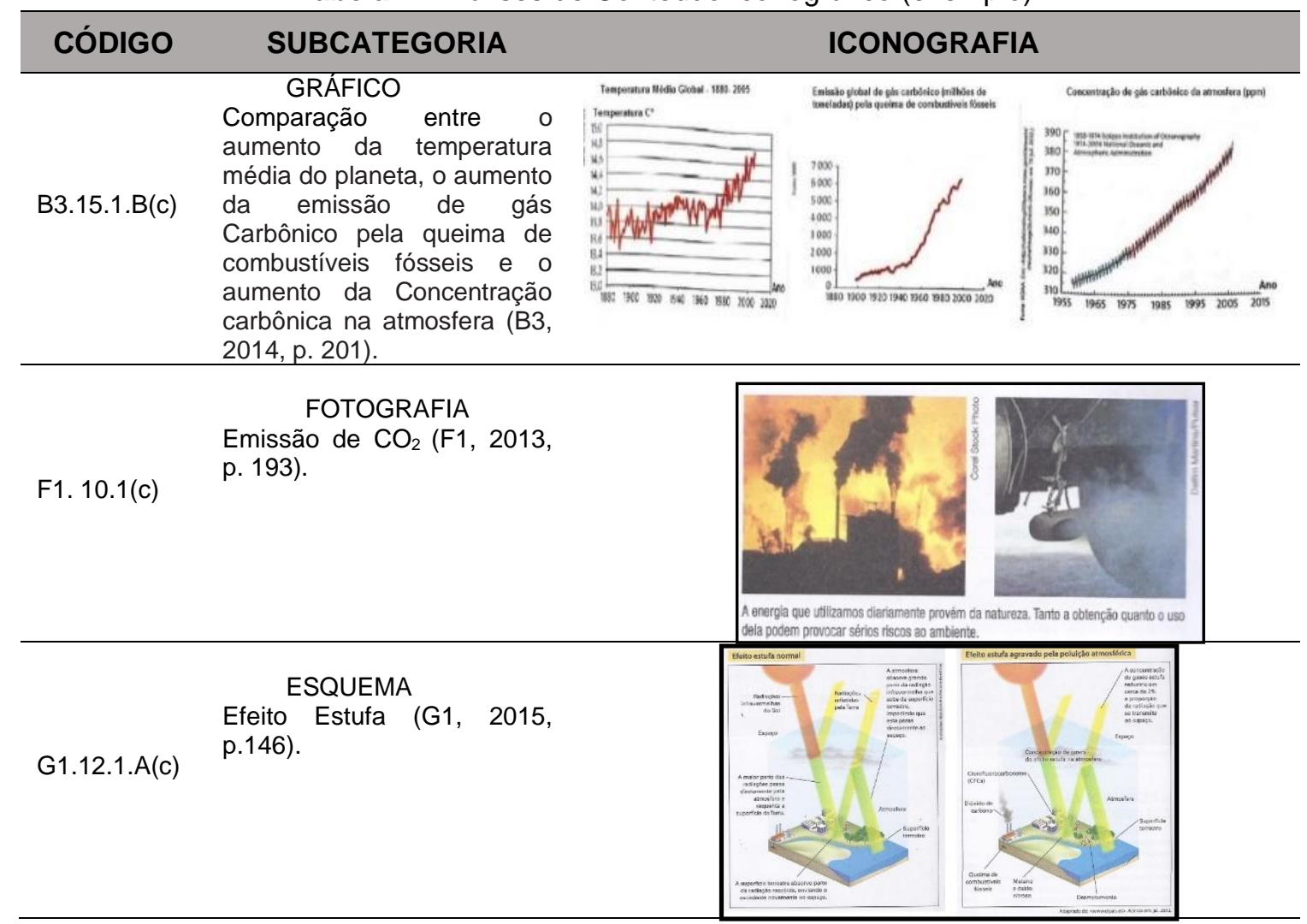

Fonte: Liotti (2019).

A Tabela 5 (Análise das Atividades Propostas) apresenta a seleção referente às subcategorias: reprodução de conteúdo; interpretação de dados/investigativa e pesquisa/ discussão e debate. Para a análise das atividades foram consideradas suas características e peculiaridades no sentido de compreender se as propostas possuíam caráter fundamentalmente descritivo e interpretativo ou se essas propiciavam debates, investigação e pesquisa 
Tabela 5: Análises das Atividades Propostas (exemplos).

\begin{tabular}{|c|c|c|}
\hline CÓDIGO & CATEGORIA & ATIVIDADE \\
\hline $\begin{array}{l}\text { B3.10.15.1 } \\
\text { (sa) }\end{array}$ & $\begin{array}{l}\text { Reprodução de } \\
\text { Conteúdo }\end{array}$ & 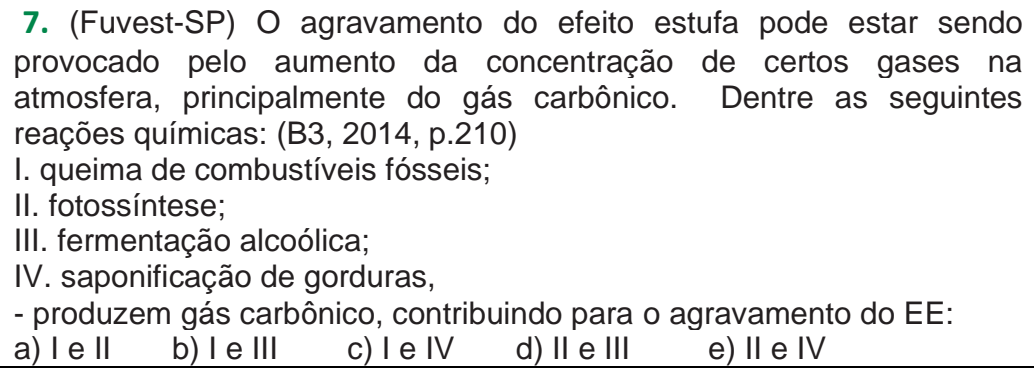 \\
\hline $\begin{array}{l}\text { G1.12.2.R } \\
\mathrm{C}(\mathrm{sa})\end{array}$ & $\begin{array}{l}\text { Interpretação } \\
\text { de dados/ } \\
\text { Investigativa }\end{array}$ & $\begin{array}{l}\text { Atividade 3. Hoje, a China já se tornou o maior emissor de CO2 do } \\
\text { planeta. No entanto, o maior poluidor per capita continuam sendo os } \\
\text { Estados Unidos. (Revista Aquecimento Global. São Paulo: Ed OnLine, } \\
\text { ano 1, n.2, p.47). } \\
\text { a) Que peso a China e Estados Unidos têm na economia mundial? } \\
\text { A partir do sec. XVIII houve um aumento da concentração de CO2 } \\
\text { na atmosfera. Qual a relação entre o desenvolvimento industrial e } \\
\text { emissão de gás carbônico? (G1, 2015, p.154). }\end{array}$ \\
\hline $\begin{array}{l}\text { B3.10.15.1 } \\
\text { (sa) }\end{array}$ & $\begin{array}{l}\text { Pesquisa/ } \\
\text { discussão e } \\
\text { Debate }\end{array}$ & $\begin{array}{l}\text { A) Em grupos (pesquisa e debate sobre o tema: aquecimento global) } \\
\text { que deve contar com o apoio dos professores de Física. O estudante } \\
\text { deve apresentar os resultados da pesquisa para a classe e para a } \\
\text { comunidade escolar, pois esse é um problema importante e de muito } \\
\text { interesse para todas as pessoas, do Brasil e do mundo. B) Vídeo: Uma } \\
\text { verdade inconveniente (Paramount, 2006), baseado no livro de mesmo } \\
\text { nome. Após definidas as categorias de análise e organização das } \\
\text { tabelas buscou-se analisar detalhadamente o conhecimento } \\
\text { apresentado pelos livros didáticos ao discutir a temática das mudanças } \\
\text { climáticas, obtendo-se os seguintes resultados e discussões: }\end{array}$ \\
\hline
\end{tabular}

Fonte: Liotti (2019).

Após definidas as categorias de análise e organização das tabelas buscou-se analisar detalhadamente o conhecimento apresentado pelos livros didáticos ao discutir a temática das mudanças climáticas, das quais os resultados e discussões serão apresentados a seguir.

\section{O que dizem os textos dos livros didáticos sobre mudanças climáticas: resultados e discussões}

Observou-se a presença de uma visão ocidental eurocêntrica das mudanças climáticas, a qual não questiona o modelo econômico dominante que o produz, pois não apresenta nenhuma das consequências negativas dos países do Norte e omitem os efeitos sobre os países em desenvolvimento do Sul, além de adotar uma invisibilidade em relação às mulheres e às crianças, constatada pela sua ausência nesta discussão (SERANTES-PAZOS, 2015). Não há intensão de apresentar as questões sociais que estão "por trás" das políticas públicas, as controvérsias científicas, não contribuindo para a construção do conhecimento escolar e a formação científica dos estudantes, numa perspectiva de superar esta visão superficial acerca do fenômeno climático (LIOTTI, 2019). 
Evidenciou-se uma tendência conteudista-disciplinar. Nos livros de Química, a temática das mudanças climáticas relaciona-se à discussão acerca da estrutura dos gases, poluição térmica e aspectos dinâmicos das transformações químicas, enquanto nos livros de Biologia, concentra-se nos ciclos biogeoquímicos. Nos livros de Física, em mecânica e nas fontes de fluidos, energia e, em Geografia, poluição do ar, impacto ambiental, tipos de clima e fontes de energia (LIOTTI, 2019).

Constatou-se pela análise textual dos conteúdos a falta de uma abordagem interdisciplinar e contextualizada sobre a temática das mudanças climáticas que evidenciasse a complexidade dos fatores astronômicos, geofísicos e atmosféricos que envolvem esse fenômeno. Observou-se a presença de informações reducionistas e convencionais sobre o problema, muito focadas na dimensão ambiental, ignorando-se sua dimensão social, fora das recomendações do IPCC (2014) e sem propostas pró-ambientais realistas e de compromisso ecossocial (SERANTES-PAZOS; MEIRA-CARTEA, 2016).

Assinala-se, também, que não se reconhecem nos textos dos livros didáticos as controvérsias científicas, modelos e cenários que trabalham as incertezas que envolvem os fenômenos climáticos, sendo este um componente essencial da Ciência para a construção do conhecimento escolar pelo estudante. Edgar Morin salienta que a incerteza como princípio é uma necessidade permanente de educação: "a incerteza que destrói o conhecimento simplista é o desintoxicante do conhecimento completo" (MORIN, 2001, p. 41); como também ressalta que a necessidade de uma consciência da multidimensionalidade diante de visões disciplinares, especializadas e parciais, porque empobrecem: "a consciência da complexidade e nos faz entender que nunca podemos escapar da incerteza e que nunca podemos ter conhecimento total" (MORIN, 1998, p. 101).

Constata-se que o desenvolvimento de uma consciência ambiental multidimensional está atrelado a uma formação científica de qualidade que proporcione aos estudantes, por meio do processo educativo, articular a teoria com a prática a partir de sua subjetividade, bem como, que permita promover e avançar na compreensão teórica do problema, possibilitando o rompimento com a imobilidade atual, incoerente como uma formação ambiental cidadã, que reivindica uma postura crítica com o intuito de construir alternativas aos modelos hegemônicos de desenvolvimento.

Considerando-se a importância de outras formas de comunicação além da textual na formação do conhecimento científico, e reconhecendo-se que os livros didáticos estão cada vez mais ilustrados, estes fatos conduziram a análise da representação do fenômeno climático implícito nas iconografias como fontes facilitadoras no processo de aprendizagem.

Quanto à análise iconográfica, nos livros didáticos constata-se que 7\% eram mapas, $13 \%$ gráficos, $27 \%$ esquemas e $53 \%$ fotografias; Em geral, os mapas, que representam como o aumento de temperatura ou agentes meteorológicos extremos afetam o território, são genéricos, dificultando a 
localização da população representada (no mapa) e os efeitos em seu território; os gráficos referem-se ao aumento de temperatura, emissões de $\mathrm{CO}_{2}$ ou consumo de energia. Também são representações genéricas apontando efeitos globais catastróficos, não observando gráficos de representação do território local; os esquemas representam preferencialmente os ciclos biogeoquímicos, principalmente o efeito estufa; as fotografias são ícones de mudanças climáticas que mostram cenas de risco ou desastres naturais (ursos polares, cenas de degelo, fontes de poluição do ar, etc.) e quase nunca apresentam pessoas, mas, quando o fazem, são racializadas, empobrecidas e muito diferente dos alunos que usam os livros.

Concorda-se com Pralon (2012) ao afirmar que não reconhecemos a função cognitiva da imagem relacionada ao contexto pois, em geral, a iconografia usada não é relevante para os estudantes, as imagens utilizadas não despertam empatia e não facilitam o entendimento das mudanças climáticas, embora forneçam informações sobre algumas das causas e efeitos. Perde-se, portanto, segundo Pralon (2012, p. 163), o "potencial pedagógico das imagens em situações didáticas [...] as quais são capazes de transmitir mensagens, conceitos, ideias, valores, desempenhando, desse modo, importante papel na formação dos jovens".

Evidenciou-se pela análise das atividades, atendendo as categorias apresentadas, o seguinte resultado: $11 \%$ se caracterizam por atividades de interpretação de dados, as quais requerem o estabelecimento de relações entre diferentes conhecimentos em busca da resposta; 33\% são tarefas com propostas de pesquisa, envolvendo apresentação e debate, e 56\% são tarefas com propostas de reprodução de conteúdos ou de anotações a partir de textos já estudados.

Salienta-se que as atividades não ajudam a interconectar informações, causas e consequências, principalmente no que se refere aos hábitos e modos de vida dos estudantes. Também não ajudam a ter uma visão profunda e complexa do problema, mesmo na presença de atividades que propõem a pesquisa como busca de aprimoramento do conhecimento sobre o fenômeno climático. Como a grande maioria requer apenas a reprodução do conteúdo estudado, as atividades presentes nos livros analisados não contribuem efetivamente para a construção de um conhecimento escolar sobre as mudanças climáticas.

Sob o ponto de vista pedagógico e considerando-se todo o potencial que o livro didático possui em veicular conhecimentos e possibilidades de acesso a diferentes conteúdos em diferentes contextos, utilizando-se de diferentes argumentos para viabilizar processos de reflexão sobre temas complexos e controversos, como é o caso das mudanças climáticas, os livros didáticos não deveriam ser considerados simplesmente sistemas de transmissão de dados, mas sim fonte de conhecimento escolar que oportuniza a análise crítica da realidade. 
A análise do conteúdo textual dos livros didáticos mostrou claramente que não há um enfoque interdisciplinar e contextualizado sobre as mudanças climáticas, não se evidencia a complexidade dos fatores astronômicos, geofísicos e atmosféricos que envolvem este fenômeno, assim como se excluem do texto a reflexão sobre as consequências sociais.

Nos textos analisados, percebe-se que não se apresenta as controvérsias científicas, os modelos e cenários de estudos das mudanças climáticas relacionando-as com as incertezas que envolve o fenômeno como um componente substancialmente científico, discutível ou refutável, como qualquer conhecimento científico. Portanto, a construção do conhecimento sobre mudança climática, a partir dos textos dos livros didáticos, por não trazer a possibilidade de promover diferentes discussões, com diferentes argumentos, viabilizando processos de confirmações ou refutações de determinada teoria, reconhecendo a força desse propósito como parte inerente da Ciência, torna-se simplista e distante da realidade.

Desse modo, entende-se que os conteúdos apresentados nos livros didáticos perderam e estão perdendo a oportunidade de contribuir para a ampliação da compreensão crítica do fenômeno a partir do contexto escolar, fato que poderia vir a subsidiar a formação de cidadãos protagonistas e conscientes de sua realidade, capazes de pensar e construir ações ambientais individuais e coletivas na vida cotidiana.

\section{Conclusões}

Diante dos resultados dessa pesquisa, percebe-se que ainda há muito em que se modificar, atualizar e propor enquanto conteúdo textual, atividades e iconografias para que o livro didático possa contribuir para que os estudantes construam concepções científico-sociais, econômicas e políticas sobre o fenômeno das Mudanças Climáticas.

Nessa perspectiva epistemológica, a abordagem do saber científico presente nos livros didáticos acerca das mudanças climáticas "tem perdido em grande parte o seu poder por uma racionalidade social dominada por meios culturais preocupados com a desconstrução da realidade" (SERNTES-PAZOS, 2016, p. 162), privando-se nesse caso da oportunidade de construção do saber na instituição escolar pelos estudantes.

Os livros didáticos, com relação às mudanças climáticas, têm reforçado um modelo tradicional de ensino apresentando-as com um caráter acessório ao currículo, com tratamento superficial em relação aos aspectos científicos relevantes que poderiam contribuir para a compreensão do fenômeno em sua totalidade.

Observou-se nos livros didáticos uma abordagem secundária com relação às mudanças climáticas, ou seja, esta é frequentemente tangenciada e tratada de forma reducionista. As abordagens simplificam, menosprezam e 
ignoram os avanços científicos a respeito do tema, evidenciando ausência de uma discussão profunda e mais adequada sobre as causas e consequências que envolvem esta temática, propiciando uma visão distorcida da Ciência, tratando-a como neutra, desprovida de interesses e altruísta (SERANTESPAZOS, 2016).

Justamente nesse cenário, é imprescindível que se estabeleça uma reflexão sobre o papel do ensino de Ciências na atualidade, no sentido de se revelar a importância dessa formação para os jovens estudantes que, em grande parte, encontram no processo de sua escolarização básica a única oportunidade de acesso ao conhecimento científico escolarizado.

Essas evidências apontam para a demanda de uma estruturação curricular que propicie uma abordagem efetiva acerca das mudanças climáticas, tanto no processo educativo, quanto nos conteúdos presentes nos livros didáticos e uma corresponsabilidade das editoras em sua publicação, no sentido de assumirem um compromisso de adotar uma linguagem científica e apropriada para os estudantes do Ensino Médio.

Neste contexto, os livros didáticos podem desempenhar um papel importante na construção do conhecimento sobre as mudanças climáticas, tanto por parte dos professores, quanto pelos estudantes. Para isto, é necessário que haja ações políticas eficazes para resolver o problema. Ações, que priorizem investimentos na formação inicial e continuada dos professores, com a finalidade de proporcionar aos docentes (professores) conhecimentos teóricos e práticos dirigidos à uma formação crítica e cidadã. Considera-se ainda imprescindível potencializar e proporcionar condições físicas e estruturais para as escolas, equipando-as de forma que possam cumprir seus objetivos (LIOTTI, 2019). É relevante também salientar que ninguém está imune às consequências das mudanças climáticas que perturbam ao limite os ciclos vitais da natureza. Nesse sentido, sugere-se algumas das possibilidades de ações a serem desenvolvida no espaço escolar:

1. A incorporação do debate de temas complexos e controversos no processo educativo, como um meio de revelar que a Ciência não é neutra, mas sim um caminho de reorganização, de experiência e de produção de conhecimento que requer a união de diferentes áreas do conhecimento para a sua compreensão.

2. O entendimento de que nenhuma característica do Planeta pode ser estudada como resultado de causalidade única (relação causa-efeito), mas sim como integração de todos os processos terrestres que constituem a base para o entendimento de sua dinâmica e, por conseguinte, para a realização de previsões a seu respeito.

3. A promoção da formação dos professores para instrumentalizá-los com conhecimentos científicos suficientes sobre as mudanças climáticas, de forma que eles possam orientar, mais 
satisfatoriamente a aprendizagem dos estudantes, superando a ausência de cientificidade dos textos dos livros didáticos.

4. O incentivo ao diálogo entre a sociedade civil, os cientistas e os governantes para que juntos possam construir uma sociedade alternativa que suporte a demanda do crescimento econômico e populacional do séc. XXI.

Em vista disso, se reconhece o grande desafio que significa 0 enfrentamento da crise socioambiental climática. Nesse momento, mais do que nunca, é fundamental que haja o compromisso de romper com os obstáculos institucionais para se alcançar uma sustentabilidade ambiental, diluindo a lógica tecnocrática e reducionista para apresentar uma visão mais crítica, na linha da corresponsabilidade e da justiça socioambiental.

\section{Agradecimentos}

Ao Conselho Nacional de Desenvolvimento Científico e Tecnológico $(\mathrm{CNPq})$, pelo apoio financeiro à pesquisa; à Universidade Federal do Paraná, por tornar possível o doutoramento do autor.

\section{Referências}

APPLE, M. El libro de texto y la política cultural. Revista de Educación, n. 341, p. 109-126, 1993.

APPLE, M. Trabalho docente e textos: economia política das relações de classe e de gênero em educação. Trad. Thomaz T. da Silva, Tina Amado e Vera M. Moreira. Porto Alegre: Artes Médicas, 1995.

APPLE, M. Teoria crítica y educación. Buenos Aires: Minoi y Ávila, 1997.

BATISTA, A. A. G. Um objeto variável: textos, impressos e livros didáticos. In: ABREU, Marcia (Org.). Leitura, história e história da leitura. Campinas-SP: Associação de Leitura do Brasil: Fapesp, 1999.

BARDIN, L. Análise de conteúdo. 4 ed., Lisboa: Edição 70, 2008.

BITTENCOURT, C. M. F. Autores e editores de compêndios e livros de leitura (1810-1910). Revista da Faculdade de Educação da USP. Educação \& Pesquisa, 30 (3), 475-491, set./dez. 2004.

BITTENCOURT, C. M. F. Livros didáticos entre textos e imagens. In: BITTENCOURT, C. M. F. O saber histórico na sala de aula. $12^{\circ}$ ed. São Paulo: Contexto, 2015.

CARVALHO, L. M.; TOMAZELLO, M. G. C.; OLIVEIRA, H. T. Pesquisa em educação ambiental: panorama da produção brasileira e alguns dos seus dilemas. Caderno CEDES. Campinas, v. 29, n. 77, p. 13 - 27, jan./abr. 2009. 
CHOI, S.; NIYOGI, D.; SHEPARDON, D. P.; CHARUSOMBAT, U. Do Earth and Environmental Science Textbooks Promote Middle and High school Students' Conceptual Development about Climate Change? : Textbooks' consideration of students' misconceptions. Bulletin of the American Meteorological Society. EUA, p. 889-898, july, 2010.

FRACALANZA, H.; MEGID-NETO, J. (Org.). O livro didático de ciências no Brasil. Editora Komedi. 2006.

FREITAS, N.; RODRIGUES, M. H. O livro didático ao longo do tempo: a forma do conteúdo. Anais do 18ํㅡㄴ Seminário de Iniciação Científica, UDESC, 2007. Disponível em: <http://www.udesc.br/arquivos/portal antigo/Seminario18/18SIC/PDF/074 Neli Klix Freitas.pdf>. Acesso em: 17 mai. 2019.

GATTI-JÚNIOR, D. Livros didáticos, saberes disciplinares e cultura escolar: primeiras aproximações. Revista História da Educação. ASPHE/FaE/UFPel, Pelotas/RS, v. 1, n. 2, p. 29-50, jul./dez., 1997.

GIROUX, H. A. Cultura, política y práctica educativa. Barcelona, Espanha: Grão, 2001.

IPCC. AR5/SPM, 2014. Impacts, Adaptation, and Vulnerability. In: Climate Change. New York: Cambridge University Press. Disponível em:<https://www.ipcc.ch/report/ar5/wg2/> Acesso em: 17 mai. 2019.

LEITE, J.C. Controvérsias na climatologia: o IPCC e o aquecimento global antropogênico. Revista Scientiae Studia, São Paulo, v. 13, n. 3, p. 643-677, 2015.

LIMA, G. F. C.; LAYRARGUES, P. P. Mudança climática, educação e meio ambiente: para além do conservadorismo dinâmico. Educar em Revista. Editora UFPR, Curitiba, Edição Especial, v. 3, p. 73-88, 2014.

LIOTTI, L. C. O conhecimento escolar sobre mudança climática nos livros didáticos do ensino médio - PNLD/2015. Tese de Doutorado, UFPR, 2019. Disponível em: <https://acervodigital.ufpr.br/handle/1884/65131>. Acesso em: 3 jul. 2020.

LOPES, A. C. Conhecimento escolar: ciência e cotidiano. Rio de Janeiro: Editora da UERJ, 1999.

LOPES, A. C. Currículo e Epistemologia. Ijuí: Editora UNIJUI, 2007.

MARTINS, I. Analisando livros didáticos na perspectiva dos Estudos do Discurso: compartilhando reflexões e sugerindo uma agenda de pesquisa. In: MARTINS, I.; GOUVÊA, G.; VILANOVA, R. (Editoras). O livro didático de Ciências: contextos de exigência, critérios de seleção, práticas de leitura e uso em sala de aula. Rio de Janeiro: FAPERJ/UFRJ/NUTES, 2012. Disponível em: $<$ http://www.nutes.ufri.br/arquivos/O livro didatico de Ciencias.pdf>. Acesso em: 17 mai. 2019. 
MININNI-MEDINA, N. Formação de multiplicadores para educação ambiental. In: PEDRINI, A.G. (Org.). O Contrato social da ciência. Unindo saberes na educação ambiental. Petrópolis: Vozes, 2002.

MORIN, E. Introducción al pensamento complejo. Barcelona: Gedisa, 1998.

LOPES, A. C. Los siete saberes necesarios para la educación del futuro. Barcelona: Paidós, 2001.

PRALON, L. Imagem e produção de sentido: as fotografias no livro didático. In: MARTINS, I.; GOUVÊA, G.; VILANOVA, R. (Editoras). O livro didático de Ciências: contextos de exigência, critérios de seleção, práticas de leitura e suo em sala de aula. Rio de Janeiro: FAPERJ/UFRJ/NUTES, 2012. Disponível em: $<$ http://www.nutes.ufrj.br/arquivos/O livro didatico de Ciencias.pdf>. Acesso em: 17 mai. 2019.

SERENTES-PAZOS, A. Como abordan o Cambio Climático os libros de texto da Ensinanza Secundaria Obligatória na España. ambientalMENTEsustentable, n. 20, p. 249-262, 2015.

SERANTES-PAZOS, A. Como abordan o Cambio Climático os libros de texto da Ensinanza Secundaria Obligatoria na España. AmbientalMENTE Sustentable. Revista científica galego-lusófona de educación ambiental, v. 20, n. 2, p. 249-262, 2016.

SERANTES-PAZOS, A.; MEIRA-CARTEA, P.A. El cambio climático en los libros de texto de la Educación Secundaria Obligatoria o la crónica de las voces ausentes. Documentación Social. Revista de estudios sociales y de sociología aplicada, v. 183, p. 153-170, 2016.

STEFFEN, W.; GRINEVAL, J.; CRUTZEN, P.; McNEIL L, J. The Anthropocene: conceptual and historical perspectives. Philosophicl Transaction Royal Society Journal, n. 369, p. 842-867, april 2011.

TEIXEIRA, R.F.B. Significados do Livro Didático na Cultura Escolar. Anais do $X$ Congresso Nacional de Educação/EDUCERE, PUC. Curitiba: Pontifícia Universidade Católica do Paraná, 2011. p. 9416-9426. Disponível em: $<$ https://educere.bruc.com.br/arquivo/pdf2011/5550 3648.pdf>. Acesso em: 2 jun. 2020. 